\title{
Interactive comment on "Comparison of approaches to interpolating climate observations in steep terrains with low-density gauging networks" by Juan Ossa-Moreno et al.
}

\section{Anonymous Referee \#2}

Received and published: 16 January 2019

General comments: I think the topic of the manuscript is interesting and also in the scope of HESS, as it intends to answer the relevant question: "which data sets and (interpolation) methods are most adequate to represent climatic conditions and information at altitudes higher than $1000 \mathrm{~m}$ in data scarce Chile and similar Andean regions." However, in my opinion, the manuscript in its current version is not suitable for publication and needs major revision in many aspects. The following sections need to be improved: Introduction: How have other authors addressed this topic? There is a strong discourse on this issue and a large number of researchers developing precipitation products as MSWEP, CHIRPS and CR2 have dealt with this problem. Please elaborate on the findings of other authors working with high elevation data. Also how

Printer-friendly version

Discussion paper 
do authors deal with missing information in hydrological modelling, which interpolation methods have worked and which were the results of evaluating different satellite based and combined precipitation data sets in data scarce Andean regions? Although you mention some authors, their findings are not described or compared. Ideally, these should help to justify your objectives. Data: - The data (input, validation..) should be presented in the main text. Otherwise the numbers in the map are useless. Also in the map, it would help to enlarge it and use other colours for elevation and delineate a stronger catchment area to make the map understandable even in black and white. Numbers in the map should also be visible in Figures 2 and 3 . - It is not well explained why you only used such a short period. There are enough data available to fill gaps (CR2 P dataset, Chirps, MSWEPv2.2, etc.). Temperature of course is difficult but at least different time periods could be compared. The main variable of interest should be precipitation. - Why do you present a spatial distribution of Chirps in May 2009 instead of comparing it with values from observed data? Methods section 3: - The first paragraphs of this section should be part of the introduction as they deal with the general state of the art. - The advantage of using GLMMs and its exact output in this context is not clear to me. - There should be a conceptual figure explaining the methodology, input data and outputs - You use station data and as Covariates Chirps and ENSO as model input to test different interpolation methods. Then in the results section you correlate station data with Chirps and other data products for the station pixel? This part should be shifted to the data section and justify the method and data input (or not?). 4.1 difference between input data and validation data not presented Results: In light of the above described missing information regarding the data input, validation data and output variables, it is difficult to understand the results and their interpretation. Overall presentation structure and language are still very poor. There are too many figures with little information content. Please focus on the main findings and try to present them in fewer self-explanatory figures.

Interactive comment on Hydrol. Earth Syst. Sci. Discuss., https://doi.org/10.5194/hess-2018-

Printer-friendly version

Discussion paper 
505, 2018.

HESSD

Interactive

comment

Printer-friendly version

Discussion paper

(c) (i) 